\title{
МАРКЕТИНГОВОЕ ИССЛЕДОВАНИЕ РЫНКА БАНКОВСКИХ ПРОДУКТОВ ГРУЗИИ
}

\author{
Хатуна Шаламберидзе, доктор экономики, Государственный университет Акакия Церетели; \\ ассоииированный профессор, Кутаисский университет, г. Кутаиси, Грузия \\ Наргиза Каркашадзе, доктор администрирования бизнеса, Государственный университет \\ Акакия Церетели, ассоииированный профессор, г. Кутаиси, Грузия
}

\section{DOI: https://doi.org/10.31435/rsglobal_conf/25052021/7561}

Abstract. Today, the Georgian banking system is still at the stage of transformation and constant changes and it has not gone through all the stages of preparation for the market. The state is constantly striving to have healthy competition in the banking market and get the maximum result that the market can afford. According to the data published by the National Bank of Georgia, today 15 officially licensed commercial banks are officially registered, out of which 14 banks have foreign capital, which naturally sets high competition and standards. That is why it is important for banks to create products that will be acceptable to consumers. Banking products are becoming so necessary for everyday life that the interest and aspiration towards it is growing daily. From the above it becomes important to the bank Clients or the interested public to have complete and complete information about it.

Keywords: Transformation of the banking system in Georgia; Healthy competition in the Banking Market; Determining consumer attitudes towards Banking Products.

Введение. Во всем мире финансовая сфера - это место, где можно заработать много денег, что увеличивает конкуренцию. Поэтому необходимо постоянное развитие. Развитие финансовой системы положительно влияет как на интересы населения, так и на национальную экономику. Банковская система имеет большое значение для развития экономики, соответственно, для страны актуальны ее успех и безупречное функционирование.

Сегодня банковская система Грузии все еще находится на этапе трансформации и постоянных изменений, и она не прошла все стадии подготовки к выходу на рынок. Государство постоянно стремится к здоровой конкуренции на банковском рынке и к максимальному результату, который рынок может себе позволить. Согласно данным, опубликованным Национальным банком Грузии, сегодня официально зарегистрировано 15 лицензированных коммерческих банков, из которых 14 банков имеют иностранный капитал, что, естественно, устанавливает высокую конкуренцию и стандарты. Именно поэтому банкам важно создавать такие продукты, которые будут приемлемы для потребителей. Банковские продукты становятся настолько необходимыми в повседневной жизни, что интерес и стремление к ним растут с каждым днем. Исходя из вышесказанного становится важным, чтобы клиенты банка или заинтересованная общественность имели полную и совершенную информацию, в связи с этим.

Для того, чтобы коммерческие банки достигли намеченной цели, необходимо активизировать и улучшить роль маркетинговых исследований, в частности, в отношении банковских услуг. Маркетинг играет важную роль в развитии любого бизнеса, но он также особенно «чувствителен» в банковском деле. Новая реальность потребовала от бизнеса совершенно иных ответов на, казалось бы, уже известные, часто задаваемые вопросы. Маркетинг как посредник между бизнесом и потребителями оказался одним из первых на «передовой». Предполагается, что коронавирус создаст необходимость обновить свою маркетинговую роль и подходы, чтобы компании, находящиеся в режиме форс-мажора, могли лучше понять текущие потребности пользователя. Не только для того, чтобы отвечать на их запросы, но и для самостоятельного создания и управления этим запросом. Учитывая сложившуюся ситуацию, одной из основных задач маркетинга маркетологи называют его быструю цифровизацию и отмечают, насколько хорошо разные отрасли справляются с этой задачей, в значительной степени зависит от их предыдущего опыта и в целом специфики бизнеса, степени цифровизации своей деятельности. digital-маркетинг или цифровой маркетинг - включает маркетинговую деятельность, направленную на привлечение 
пользователей через Интернет и превращение их в клиентов. Например, банковский сектор в этом отношении оказался более развитым. ${ }^{1}$

Цель. Целью исследования статьи является определение отношения потребителей к банковским продуктам и определение наиболее актуального и желательного для них банковского продукта или услуги.

Методы исследования. В статье используется метод опроса, в частности онлайн-опрос.

Основная часть. Для того, чтобы банки успешно выполняли свое дело, важно разработать новые методы и формы работы, которые будут использоваться в будущих отношениях с клиентами. Поэтому банку нужны маркетинговые департаменты. Маркетинговый департамент банка основан на определенных принципах, в соответствии с которыми затем функционируют. Маркетинг помогает банкам преодолевать значительные трудности и препятствия, в результате чего различные стратегии облегчают им выход на рынок и закрепление на нем места. Маркетинговый подход к банковскому делу обеспечивает успех банковского дела. Банки вовлечены в жесткую конкуренцию, именно для того, чтобы занять на рынке конкурентное место, банку необходимо иметь службу маркетинга, чтобы успешно осуществлять свою деятельность. Маркетинговые службы банка предоставляют: поиск необходимой информации, разработку маркетинговой стратегии, создание нового типа банковских услуг и продуктов, доставку их конечному потребителю, а также управление различными маркетинговыми мероприятиями.

Уточним, что означает маркетинговый подход к банковскому делу. Он обеспечивает планирование деятельности такого вида, который связан с созданием, распространением и предоставлением потребителям банковских услуг и банковских продуктов. Когда интересы обоих субъектов банка и клиентов защищены и принимаются во внимание, формируются здоровые отношения. С одной стороны, клиент остается довольным, а с другой - банк успешно реализует намеченные планы.

Банк продает продукт - деньги и услуги, предлагаемые клиентам различными способами. К ним относятся как традиционные продукты сервиса (оплата, может быть как наличная, так и безналичная, депозиты, ссуды и т.д.), так и нетрадиционные виды.

Продажа банковских продуктов и услуг для любого банка является важным этапом в процессе его деятельности. Однако пандемия коронавируса существенно изменила поведение потребителей. Сегодня грузинские банки вовлечены в жесткую конкуренцию, и им приходится работать в условиях этой конкуренции. В этих условиях банкам следует постараться создать максимально выгодные и ориентированные на клиента условия. Но часто банки настолько вовлечены в конкуренцию друг с другом, что забывают потребителя. Реальность такова, что они меняют продукты только из-за конкурентного преимущества, а не потому, что это выгодно для потребителя. Именно определение стратегии банковского маркетинга помогает банкам создавать наиболее благоприятные условия, поэтому очень важно формирование банковских стратегий.

Маркетинговая стратегия заключается в выборе наилучших путей успешного выполнения поставленных перед банком целей и направлений развития, которые намечены банком. Для коммерческих банков очень важно выбрать и установить конкретные цели, потому что тогда их путь и план действий должны проводится в этом направлении. Когда банк ставит перед собой конкретные цели, он уже четко представлен и позиционируется на рынке. Представление целей банка также важно, поскольку сотрудники, клиенты, акционеры и другие заинтересованные стороны должны иметь четкое представление о предназначении банка и их планах на будущее.

У каждого банка есть маркетинговая стратегия, посредством маркетинговой стратегии банка должны быть определены следующие элементы: 1) Определение рынка и целевых сегментов; 2) Определение долгосрочных и краткосрочных целей банка на рынке; 3) Элементы банковского маркетинг-микса.

Для того, чтобы банки преуспели на финансовом рынке, необходимо удовлетворять потребности клиентов, такие как: скорость, форма и содержание банковских услуг, удобство, доступность, простота. Соответственно, банк должен предлагать свои услуги клиентам там и в

\footnotetext{
${ }^{1}$ Retrieved from https://act-global.com/news/covid-19-

\%E1\%83\%A8\%E1\%83\%94\%E1\%83\%A1\%E1\%83\%90\%E1\%83\%AB\%E1\%83\%9A\%E1\%83\%94\%E1\%83\%91\% E1\%83\%9A\%E1\%83\%9D\%E1\%83\%91\%E1\%83\%94\%E1\%83\%91\%E1\%83\%98-\%E1\%83\%97\%E1\%83\%A3-

$\% \mathrm{E} 1 \% 83 \% 92 \% \mathrm{E} 1 \% 83 \% 90 \% \mathrm{E} 1 \% 83 \% 9 \mathrm{~B} /$
} 
то время, когда они сталкиваются с необходимостью в этой услуге. Такой подход к услугам находит отражение во внедрении современной банковской системы. Например, дистанционное банковское обслуживание и другие сервисы.

Современный банковский маркетинг отличается высокой эффективностью. Маркетинг в банковских учреждениях развитых стран тщательно организован и дает банкам высокие результаты. В экономически развитых странах банковскими услугами пользуется большая часть населения, это около $85 \%$. Аналогичная ситуация и в Грузии. Банки всегда пытаются предложить новые услуги существующим клиентам или вернуть старых клиентов с помощью новых услуг, а также пытаются привлечь новых клиентов, что для банка обходится дороже, чем поддержание существующих.

Банки постоянно пытаются внести изменения в продукты, которые они предлагают клиентам, они постоянно пытаются усовершенствовать существующие банковские продукты и предлагать их клиентам в таком виде, который им подходит. Но также следует отметить, что конкурентная ситуация на рынке усложняет эти процессы. Многие действующие в Грузии банки постоянно копируют друг друга. В результате потребители не могут делать выбор в пользу здорового образа жизни. В результате наших наблюдений мы обнаружили, что большинство банков имеют идентичные продукты, что в конечном итоге тормозит развитие рынка банковских услуг.

Продукты, которые коммерческие банки предлагают клиентам, выглядят так: депозиты; ссуды; дистанционное банковское обслуживание; пластиковые карты; страховые продукты и др.

Для банков важно предлагать клиентам такой вид продукта, который будет им выгоден с учетом экономической ситуации.

По данным Национального банка Грузии, чистая прибыль банков ежегодно растет. Это связано с ростом кредитного портфеля. Именно кредит является продуктом, который наиболее востребован и продается грузинским финансовым компаниям. Поэтому очень важно отрегулировать это кольцо. Примечательно, что в этом году резко снизились процентные ставки по кредитам, что было инициировано Национальным банком в связи с сокращением профицита в стране, а также было ужесточено кредитование. Мы считаем, что эта новая реформа должна быть очень полезной для жителей страны. Однако из-за пандемии коммерческим банкам пришлось внести существенные изменения в письменные программы развития банка. ${ }^{1}$

\section{Результаты исследования.}

Мы провели исследование по этим вопросам, в ходе которого были опрошены 90 респондентов из разных возрастных категорий.

Из проведенного нами исследования видно, что большинство респондентов, 55,6\%, пользуются кредитными продуктами, а 88,9\% пользуются услугами дистанционного банковского обслуживания (см. Диаграмму 1).

На вопрос, что потребители предпочитают при выборе банковских продуктов, наивысшие показатели имели условия обслуживания продуктом $(88,9 \%)$ и быстрое и качественное обслуживание (77,8\%) (см. Диаграмму 2).

Поэтому банкам важно учитывать все это и предлагать им упрощенные и более совершенные продукты.

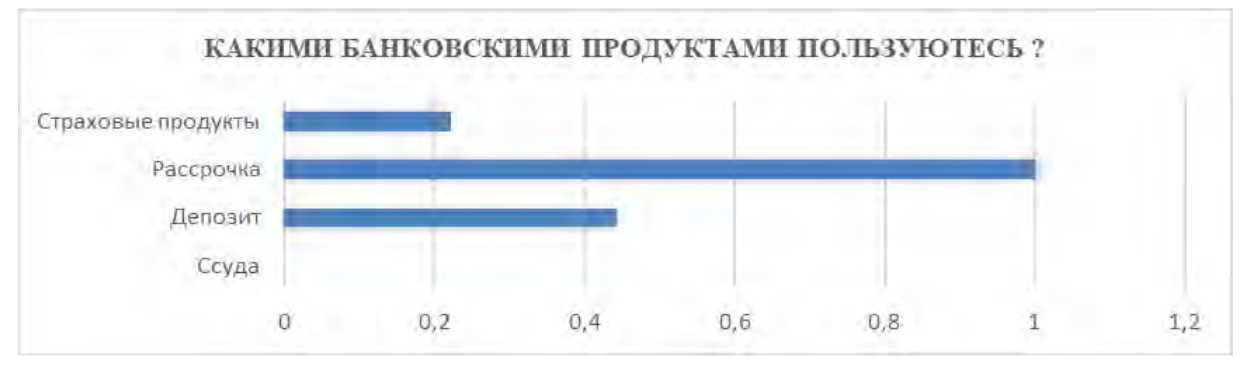

Диаграмма 1. Об использовании банковских продуктов

Источник: результаты исследования, проведенного авторами.

\footnotetext{
${ }^{1}$ Retrieved from www.nbg.ge
} 
Исследования показывают, что у банков нет надлежащей коммуникации с клиентами. Они полностью не информируют клиентов о продуктах, что также доказывает, что они не проводят достаточную маркетинговую деятельность, чтобы напрямую информировать всех клиентов о продукте и условиях обслуживания. Исследование также показывает, насколько клиенты довольны услугами банков, где результаты распределяются следующим образом: довольны $66,7 \%$, я ожидал большего - 33,3\%.

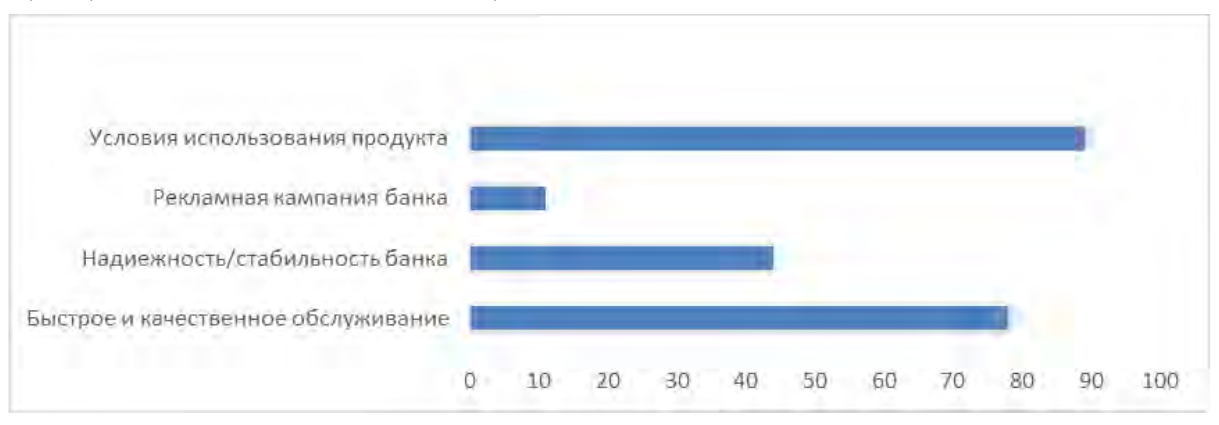

Диаграмма 2. Удовлетворенность клиентов услугами

Источник: результаты исследования, проведенного авторами.

Исследование показало, что клиенты больше всего хотят ссуды с относительно низкими процентными ставками - 88,9\%, а также с улучшенными услугами и тарифами - $100 \%$ (см. Диаграмму 3). Исходя из этого банкам лучше снизить процентные ставки и улучшить обслуживание. В результате это принесет им больше прибыли в будущем.

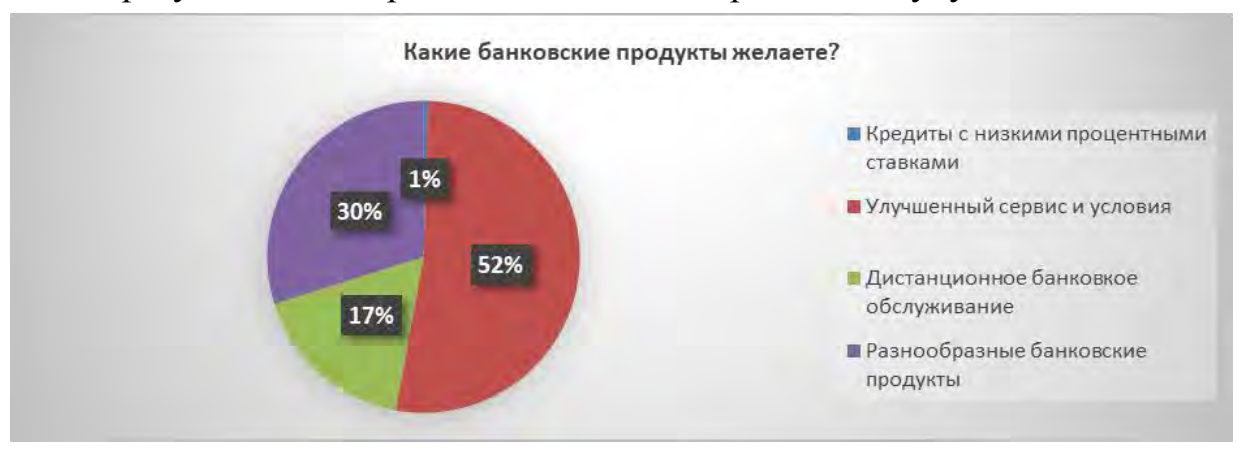

Диаграмма 3. О будущем выборе банковского продукта.

Источник: результаты исследования, проведенного авторами

Выводы. Таким образом, на основе анализа проведенного исследования можно сделать сводную оценку. В частности, большинство респондентов используют кредитные продукты и при этом активно пользуются услугами дистанционного банковского обслуживания. Также потребители предпочитают быстрые и качественные услуги при выборе банковских продуктов, а при использовании кредитных продуктов - низкие процентные ставки, разнообразные банковские услуги, хотя большинство из них не прибегает к инновационным средствам современных платежей. Поэтому банкам важно учитывать требования клиентов, предлагать им упрощенные и изысканные банковские продукты.

\section{REFERENCES}

1. Kovzanadze I. Modern banking: theory and practice, Sezani Publishing House, Tbilisi, 2014.

2. Official website of the Ministry of Finance. Retrieved from https://mof.ge/.

3. Official site of the National Bank of Georgia. Retrieved from https://www.nbg.gov.ge/index.php?m=2.

4. Site of the National Statistical Office of Georgia. Retrieved from https://www.geostat.ge/ka.

5. Work "The role of marketing in working with corporate clients of the bank." https://tekomai.wordpress.com.

6. Internet edition "Society and Banks". Retrieved from http://sab.ge/ge/usefulinfo/articles.

7. Namchavadze B. "How the banking system of Georgia is developing", 2016. Retrieved from http://forbes.ge/news/1674/rogor-viTardeba-qarTuli-sabanko-sistema.

8. Gvalia T. "New banking rules", Tbilisi, 2018. Retrieved from https://forbes.ge/news/4387/axali-sabankoregulaciebi. 